\title{
A Novel Load Shedding Strategy for Distribution Systems with Distributed Generations
}

\author{
Haotian Zhang, Member, IEEE, Chun Sing Lai, Student Member, IEEE, Loi Lei Lai, Fellow, IEEE
}

\begin{abstract}
Frequency stability is one of the key targets needed when an islanding operation occurring in a distribution system or a microgrid. To balance the generation and demand all the time, load shedding may need to apply to a distribution system or a microgrid which disconnected from the main grid. However, it is difficult to determine the accurate amount of load to be reduced in a real system, as the frequency is changing all the time. In addition to this, economic factors including reliability index and consumers' willingness need to be taken into accounted when making the decision except ensuring system stability. This paper proposes a novel load shedding strategy by considering power stability with economy in load shedding for a distribution system with distributed generations such as CHP, small wind and solar panels. The proposed strategy by classifying load into heavy and light groups is adopted, ranking is based on willingness to pay, frequency threshold and rate of change of frequency (RoCoF). The proposed method is applied to a low voltage distribution 33-bus system and the simulation was carried out with DIgSILENT.
\end{abstract}

Index Terms-Load shedding; smart grid; under-frequency relay; distribution system

\section{INTRODUCTION}

$\mathrm{P}$ OWER STABILITY is critical to the system operation and quality of supply. Any power system imbalance between load and generation, which can be caused by load variations or generation closure, will immediately result in an overall frequency change in the system. Frequency dropping, caused by demand excess, may be much more difficult to control rather than frequency increasing due to generation excess. Generation excess can be easily solved by tuning the speed governor and limiting the output power, while demand excess can only be relieved by load curtailment to maintain the frequency at an acceptable level. A low system frequency can cause destructive damage to the system components, such as the stream turbines of a generator. For example, nuclear power plants usually act as base loads are strictly operated at a frequency above $48 \mathrm{~Hz}$, whereas some hydro units may work with a frequency as low as $45 \mathrm{~Hz}$ for frequency balancing purposes. Manual disconnecting load to assist the grid stability largely depends on power system operators' experience and judgments which may lead to

Hao-Tian Zhang and Loi Lei Lai are with State Grid Energy Research Institute, Beijing, China. He is now on leave from City University London, UK. (Email: haotian.zhang.1@ city.ac.uk, lailaili@sgeri.sgcc.com.cn)

Chun Sing Lai is with Energy and Power Group, University of Oxford, UK. (chun.lai@eng.ox.ac.uk) mal-operations, whereas automatic disconnecting predetermined loads may provide a fast response for load shedding schemes but requires deliberately designed control strategies and robust control systems. With the increase in distributed generation in smart grid recently, especially the non-dispatched resources like wind and solar, the frequency stability will have a negative effect when the system suffering from islanding. The reason is that with the large increase in penetration of non-dispatchable energy sources like solar and wind, system inertia will be reduced heavily which may be negative for power system frequency stability due to the islanded system energized by large amount of converter-based decoupling generations.

In recent years, smart grid technologies have been proposed in order to meet the increased requirements for reliable, efficient and economical power grids. On this occasion, a large number of innovative technologies, advanced schemes and novel network architectures have been proposed to be implemented in the power systems, which are dedicated to make the power grids "smarter". Communication technologies allow the loads to be reduced in a standalone system determined in a centralized control centre. Bus-transfer and load shedding application with more beneficial communication-assisted schemes based on IEC 61850 is introduced in [1]. A load shedding scheme with comprehensive features which form the main part of the SCADA system was explained in [2]. The requirement of a modern load shedding system and the new intelligent load shedding scheme was reported in [3]. In addition to the novel schemes, plenty of creative optimal algorithms are applied to the load shedding technology to optimize the load shedding amount and steps. Genetic algorithm applied into load shedding scheme to minimize the shed load at all stages and maximize the lowest swing frequency was proposed in [4]. A mixed-integer linear program was proposed in [5] to set load shedding under-frequency relays. Neural network algorithms applied to the power system for adaptive load shedding was demonstrated in [6].

Besides frequency, rate of change of frequency (RoCoF, $\mathrm{df} / \mathrm{dt}$ ) is one of the important indices to determine the load curtailment. The magnitude of the disturbance estimated by $\mathrm{df} / \mathrm{dt}$ is presented to design an adaptive load shedding scheme in [7]. An Under-Frequency load shedding (UFLS) by considering $\mathrm{f}$ as a main index and employing $\mathrm{df} / \mathrm{dt}$ as a reference was shown in [8]. There is one severe drawback for designing a UFLS by RoCoF. The frequency response of a real 


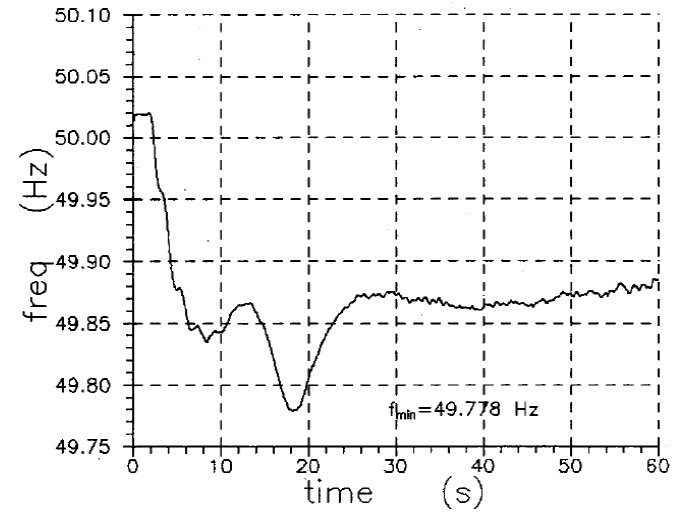

Fig. 1. Real-life power system frequency response [9]

power system is fluctuating all the time as shown in Figure 1 and this will make the RoCoF changes dramatically from positive to negative value, which means that the RoCoF value for certain period, cannot represent the trend of the frequency changing. Same as any other enterprise, power grid need to take great care about the utility profit. In a real power system, it is not only the technical aspects that need to be thought out for designing a load shedding strategy for an isolated system, but also reliability aspects together with economical issues need to be planned for distribution network operators (DNO). Load shedding based on economical consideration in power market was studied in [10]. Customer damage function and genetic algorithm were applied in [11] to minimize the sum of curtailed load and the total system interruption cost within the framework of the system operation and security constraints.

One of the important features of the future grid is that the power market allows customer to participant in the grid action and have more choices on service reliability and power quality options [13]. Customers may purchase power energy from the market and evaluating their requirement of power reliability service based on their incomes and the behavior of their power utilization. In other words, the reliability of a node is determined by the price that the customers in this node want to pay [14]. When the power system is suffering from unwanted contingency or planned power system interruption such as intended islanding based on system regulations, power system operators will evaluate the operation cost and benefit according to the customers' willingness to pay and make decision on load shedding sequence to maximize the utility profit. Consumers' Willingness To Pay (WTP) was introduced in [12] to rank the loads for further load shedding to maximize the power industries' interests. However, the profit of the DNO may not be the maximum with WTP ranking. For instance, the node with large demand but with large WTP for connection may bring less profit to the DNO than a small demand but with large WTP for connection when suffering load shedding.

This paper proposes a novel load shedding scheme based on both adaptive method and traditional method to survive the islanding system and rescue the system from collapse. Measured RoCoF was monitored and a rescue plan is made based on RoCoF to against frequency from further dropping. Load shedding sequence is determined in real-time by evaluating operating profit according to customers' WTP for
TABLE I

TYPICAL UNDER-FREQUENCY OPERATING LIMITATION FOR CHP GENERATOR

\begin{tabular}{cc}
\hline \hline Under-frequency limit (p.u.) & Operating time llowance (s) \\
$<0.01$ & Continuous \\
$0.01-0.03$ & 30 \\
$0.03-0.05$ & 15 \\
$0.05-0.06$ & 1 \\
$>0.06$ & 0 \\
\hline \hline
\end{tabular}

outages.

Section II gave a detailed explanation of the proposed load shedding methodology. Two test grids were introduced and modelled in Section III. Section IV presented simulations with different scenarios and the conclusion was given in Section V.

\section{PROPOSED LOAD SHEDDING METHODOLOGY}

The total amount of load curtailment cannot be estimated directly from the quantity of generation loss. The reason is that the governor action will save the frequency from a low level. Also the kinetic energy stored in generation units and the spinning reserve units will make up the deficit of energy supply and bring the frequency back to some extent.

With the popularity of the demand response technology and dynamic price, the load will not be increased when the grid is suffering from load deficit. As the price information will be presented in a smart meter in a "smart home", customers will re-evaluate the affordability according their incomes and the necessity of electricity consumption. DNO will adjust the real-time price in a relatively high level when the network is isolated from the main grid and suffered from a load shedding process in case of aggravating burden of power supply.

The load shedding steps can be setup according to operating limitation of the generators. In a smaller distribution system, the step size of each load shedding and number of steps need to be optimized, because each load in the system occupied a large percentage than that in a large system such as transmission network. The load may need to be measured and classified into heavy or light according to the load percentage.

For an isolated system, in general, there is no important load like industrial and commercial sectors, the power quality of the islanded network should not be as critical as that in a large power system. This paper reports the design of an automatic under-frequency load shedding strategy to survive the distribution system with distributed generations like CHP, wind and solar with consideration of economic impacts. The proposed strategy by classifying load into heavy and light groups is adopted, ranking is based on willingness to pay, frequency threshold and RoCoF. The proposed method is applied to a low voltage distribution 33-bus system and the simulation was carried out with DIgSILENT. Results will be discussed to demonstrate the benefits of this approach.

The proposed load shedding considers the load shedding steps with economical impact, frequency declined and RoCoF. Some RoCoF and Frequency threshold values are designed to achieve accurate load shedding in a distribution network. Under-frequency relay with measured $\mathrm{df} / \mathrm{dt}$ was applied to the network. 
The steps to achieve the proposed strategy are as follows:

(1) Measure the system or the most critical generator frequency continuously (usually every half a cycle).

(2) Classify the load into heavy or light according to the percentage occupied in total demand of the network.

(3) Rank each category of the loads based on willingness to pay.

(4) If frequency $f$ is less than an initial threshold, the load shedding scheme is activated. The first step of load shedding can be set to a certain percentage of the load deviation according to the swing equation which is shown in Equation (1) below. In this paper, the first step of load shedding is set to $20 \%$ of the total demand, meanwhile, the RoCoF at the relay trigger time is recorded as a reference.

$$
\Delta P=P_{m}-P_{e}=\frac{2 H}{f_{n}} \frac{d f}{d t}
$$

Where $\mathrm{Pm}$ is the mechanical power of the synchronous machine in per unit, $\mathrm{Pe}$ is the electrical power in per unit, $\Delta \mathrm{P}$ is the power difference between the generator mechanical power and electrical power, $\mathrm{H}$ is the inertia constant in seconds (normally in the range from 2 to 8 seconds [16]).

(5) When frequency f drops to lower threshold, the RoCoF value is compared to the value of the first step and the percentage of the RoCoF deviation is calculated. If RoCoF is larger than a threshold RoCoF0, the next step load shedding magnitude according to the RoCoF deviation will be determined. If RoCoF is less than RoCoF0, then stop shedding the heavy loads with the ranking order, and the light loads will be taken away.

(6) The frequency will need further fine tuning after heavy load shedding. The most direct indication is the slope of frequency, which becomes less steep. Frequency step for

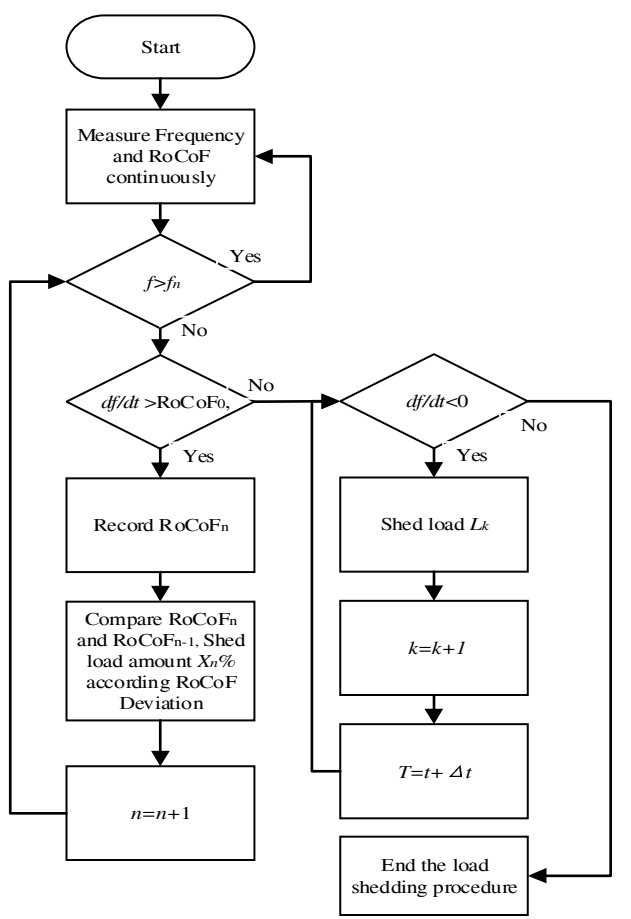

Fig. 2. Flowchart of the proposed adaptive load shedding methodology shedding light load can be smaller. The RoCoF is measured as the relay trigger signal. If the RoCoF is negative, advanced load will be taken away at the step. If the RoCoF is positive, which means the frequency is recovering and no further load needs to be taken away.

Governor requires to take further action if frequency cannot reach to the nominal value, or further load shedding needs to be conducted if the generator operates beyond the limitation which is shown in Table I.

There are two reasons to group the load into heavy and light categories. Firstly, the impact is not obvious when shedding the light load initially. However, in the fine tuning stage, the system frequency may recover significantly when shedding the light load. Secondly, from the economical perspective, the profit from light loads can be neglected, even the consumers of the light loads are willing to pay more. In a large distribution network with plenty of relays installed in the load connection, light loads may group together for a single step of fine tuning. Figure 2 demonstrates the flowchart of the proposed methodology.

The load shedding methodology consists of two stages. The first stage aims to reduce the RoCoF to a relevantly low level by shedding the heavy load. The magnitude of load shedding in each step and step size in the first stage is large. However, the number of steps in the first stage is normally not many. The second stage is to achieve the frequency recovery. The magnitude and step size are much smaller than that in the first stage but the number of steps becomes greater. This can be achieved because the RoCoF is not as steep when activating the second stage, and the time is not as critical as that in the first stage.

\section{A. Magnitude of load shedding design}

As the load is dynamic and generator droop has the capability of bringing the frequency back to a normal level, the RoCoF cannot indicate the exact load to be cut, but only with a rough estimation. However, the initial slope of the frequency decline or initial RoCoF is the only quantitative clue to estimate the level of the power disturbance [15]. A proportional relationship between load variation and RoCoF can be illustrated in Equation (1).

In [7], the author concluded that the frequency response of the electrically closer generator is greater to the disturbance location, and initial RoCoF can indicate the electrical distance from the disturbance. In other word, for the design of a distribution network, the distributed generators would be better constructed electrically far away from the external grid connection points to achieve a relatively smaller frequency response when the network is suffering from islanding. Meanwhile, load shedding starting from a relatively far away from the distribution generators could achieve better frequency response as well after the network islanding.

The adaptive load scheme with a few different steps and time delay in each step are required to examine the system frequency deviating from the nominal frequency to remain at an acceptable level. In a distribution network, the measurement point of the frequency can be set at the terminal of the most 


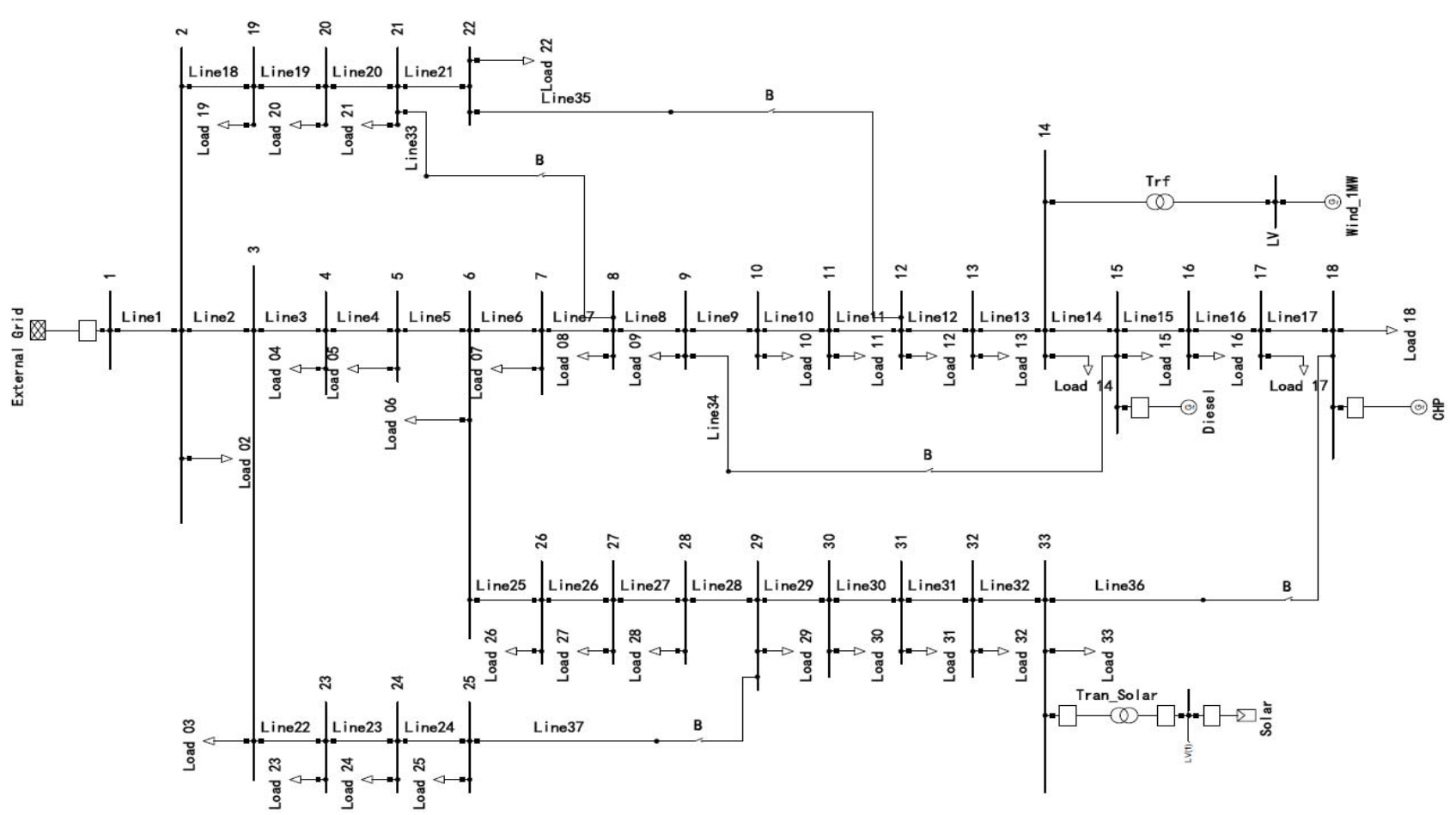

Fig. 3. IEEE 33-bus distribution test system configuration

critical distributed generator. In this paper, a typical CHP generator with operating limitation range in under-frequency scenario as shown in Table I is treated as a reference for all the study cases.

\section{B. Willingness To Pay (WTP) for Outages}

Distribution Network Operators should not only take care the profit increasing, but also satisfy customer's reliability requirements. A WTP model to investigate the WTP with planned and unplanned outage is made among Swedish households to avoid power outages in [17]. Besides WTP for connection, the profit from distribution network operation is also related to load amount per each connection, electricity price and power supply duration. For instance, a load with large demand but with less WTP for connection may bring more profit to the distribution network than a load with light demand but with more WTP for connection. However, some heavy loads in the network are important so the customer may be willing to pay more for load connection.

\section{Relay settings determination}

A measurement should be taken when the actual frequency drops to $49.5 \mathrm{~Hz}$ and the RoCoF value should be recorded, if the first frequency threshold is set at $49.5 \mathrm{~Hz}$. The first step to activate the load shedding scheme is set to $49.5 \mathrm{~Hz}$. The communication delays, calculation time and circuit breaker open time are taken into account. According to [19], the nominal range of relay tripping time period using telecommunication is between $5 \mathrm{~ms}$ and $40 \mathrm{~ms}$. If the frequency reaches the relay setting threshold value, for instance $49.5 \mathrm{~Hz}$, the circuit breaker may operates 5-10 cycles after the value 49.5 $\mathrm{Hz}$ is measured. The amount of load shedding in each step is determined by comparing the RoCoF to the previous step. For example, assuming the first step amount of load shedding is at
TABLE II

CHP GENERATOR AND GOVERNOR DATA

\begin{tabular}{l|l}
\hline \multicolumn{1}{c|}{ CHP generator } & \multicolumn{1}{c}{ Parameter } \\
\hline Power MVA & $1.8 \mathrm{MVA}$ \\
Terminal voltage & $12.66 \mathrm{kV}$ \\
\hline Speed droop $R$ & $0.065 \mathrm{p} . \mathrm{u}$. \\
Controller time constant $T_{I}$ & $0.13 \mathrm{~s}$ \\
Actuator time constant $T_{2}$ & $0.1 \mathrm{~s}$ \\
Compressor time constant $T_{3}$ & $3 \mathrm{~s}$ \\
Ambient temperature load limit $A T$ & $0.5 \mathrm{p} . \mathrm{u}$. \\
Turbine factor $K_{t}$ & $0.8 \mathrm{p} . \mathrm{u}$. \\
Frictional losses factor $D_{\text {turb }}$ & $0.001 \mathrm{p} . \mathrm{u}$. \\
Turbine rated power $P_{\text {turb }}$ & $1.44 \mathrm{MW}$ \\
Controller minimum output & 0 p.u. \\
Controller maximum output & $1 \mathrm{p} . u$. \\
\hline \hline
\end{tabular}

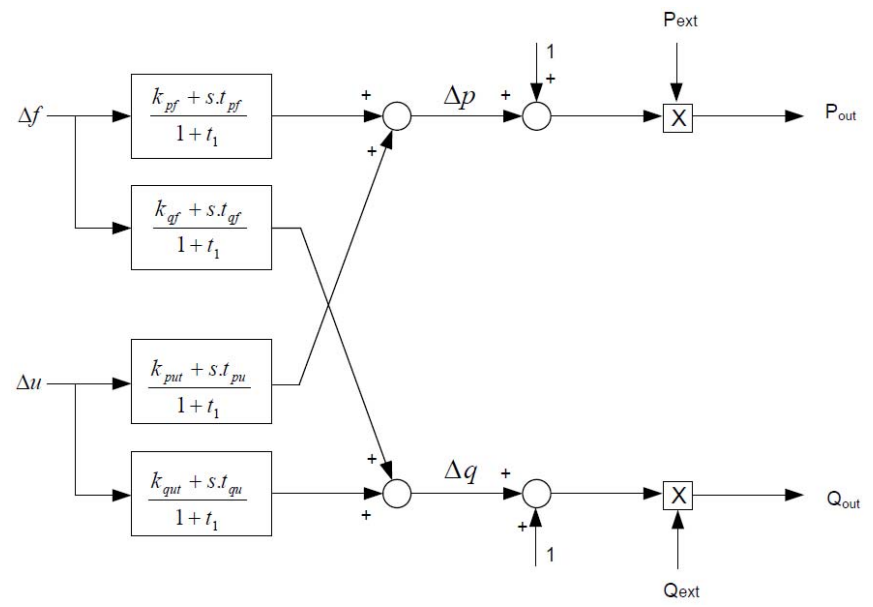

Fig. 4. The model used for simulating dynamic loads 
TABLE III

DIESEL GENERATOR AND GOVERNOR DATA

\begin{tabular}{l|c}
\hline \hline Diesel generator & Parameter \\
\hline \hline Power MVA & $0.8 \mathrm{MVA}$ \\
Terminal voltage & 12.66 \\
\hline Actuator gain $K$ & $0.5 \mathrm{p} . \mathrm{u}$. \\
$T_{1}$ & $0.2 \mathrm{~s}$ \\
$T_{2}$ & $0.3 \mathrm{~s}$ \\
$T_{3}$ & $0.5 \mathrm{~s}$ \\
$T_{4}$ & $1.5 \mathrm{~s}$ \\
$T_{5}$ & $0.1 \mathrm{~s}$ \\
$T_{6}$ & $0.2 \mathrm{~s}$ \\
Droop & $0.07 \mathrm{p} . \mathrm{u}$. \\
Combustion delay & $0.01 \mathrm{~s}$ \\
Time constant power feedback & $0.5 \mathrm{~s}$ \\
Minimum throttle & 0 p.u. \\
Maximum throttle & 1 p.u. \\
\hline \hline
\end{tabular}

TABLE IV

WIND GENERATOR AND SOLAR PANEL CAPACITY

\begin{tabular}{l|l}
\hline \hline Wind generator & Parameter \\
\hline \hline Power MVA & $1 \mathrm{MVA}$ \\
\hline Terminal voltage & $0.69 / 12.66 \mathrm{kV}$ \\
\hline Solar panel & Parameter \\
\hline \hline Power kVA & $300 \mathrm{kVA}$ \\
\hline Terminal voltage & $0.4 / 12.66 \mathrm{kV}$ \\
\hline \hline
\end{tabular}

TABLE V

A SAMPLE OF LOAD CLASSIFICATION WITH RANDOM RANKING BASED ON WTP

\begin{tabular}{|c|c|c|c|c|c|}
\hline \hline \multicolumn{3}{|c|}{ Light Loads } & \multicolumn{3}{c|}{ Heavy Loads } \\
\hline $\begin{array}{c}\text { Load } \\
\text { ranking I } \\
\text { based on } \\
\text { WTP }\end{array}$ & $\begin{array}{c}\text { Load } \\
\text { number }\end{array}$ & $\begin{array}{c}\text { Load } \\
\text { demand } \\
(\mathrm{kVA})\end{array}$ & $\begin{array}{c}\text { Load } \\
\text { ranking II } \\
\text { based on } \\
\text { WTP }\end{array}$ & $\begin{array}{c}\text { Load } \\
\text { number }\end{array}$ & $\begin{array}{c}\text { Load } \\
\text { demand } \\
(\mathrm{kVA})\end{array}$ \\
\hline $\mathbf{1}$ & 9 & $60+\mathrm{j} 20$ & $\mathbf{1}$ & 21 & $90+\mathrm{j} 40$ \\
\hline $\mathbf{2}$ & 5 & $60+\mathrm{j} 30$ & $\mathbf{2}$ & 7 & $200+\mathrm{j} 100$ \\
\hline $\mathbf{3}$ & 12 & $60+\mathrm{j} 35$ & $\mathbf{3}$ & 14 & $120+\mathrm{j} 80$ \\
\hline $\mathbf{4}$ & 6 & $60+\mathrm{j} 20$ & $\mathbf{4}$ & 19 & $90+\mathrm{j} 40$ \\
\hline $\mathbf{5}$ & 13 & $60+\mathrm{j} 35$ & $\mathbf{5}$ & 31 & $150+\mathrm{j} 70$ \\
\hline $\mathbf{6}$ & 27 & $60+\mathrm{j} 25$ & $\mathbf{6}$ & 4 & $120+\mathrm{j} 80$ \\
\hline $\mathbf{7}$ & 17 & $60+\mathrm{j} 20$ & $\mathbf{7}$ & 18 & $90+\mathrm{j} 40$ \\
\hline $\mathbf{8}$ & 28 & $60+\mathrm{j} 20$ & $\mathbf{8}$ & 3 & $90+\mathrm{j} 40$ \\
\hline $\mathbf{9}$ & 10 & $60+\mathrm{j} 20$ & $\mathbf{9}$ & 24 & $420+\mathrm{j} 200$ \\
\hline $\mathbf{1 0}$ & 15 & $60+\mathrm{j} 10$ & $\mathbf{1 0}$ & 32 & $210+\mathrm{j} 100$ \\
\hline $\mathbf{1 1}$ & 33 & $60+\mathrm{j} 40$ & $\mathbf{1 1}$ & 20 & $90+\mathrm{j} 40$ \\
\hline $\mathbf{1 2}$ & 16 & $60+\mathrm{j} 20$ & $\mathbf{1 2}$ & 23 & $90+\mathrm{j} 50$ \\
\hline $\mathbf{1 3}$ & 26 & $60+\mathrm{j} 25$ & $\mathbf{1 3}$ & 29 & $120+\mathrm{j} 70$ \\
\hline $\mathbf{1 4}$ & 11 & $45+\mathrm{j} 30$ & $\mathbf{1 4}$ & 8 & $200+\mathrm{j} 100$ \\
\hline & & & $\mathbf{1 5}$ & 30 & $200+\mathrm{j} 600$ \\
\hline & & & $\mathbf{1 6}$ & 22 & $90+\mathrm{j} 40$ \\
\hline & & & $\mathbf{1 7}$ & 2 & $100+\mathrm{j} 60$ \\
\hline & & & $\mathbf{1 8}$ & 25 & $420+\mathrm{j} 200$ \\
\hline & & & & & \\
\hline & & & & & \\
\hline
\end{tabular}

$49.5 \mathrm{~Hz}$ is $15 \%$, and the RoCoF before the relay tripping is recorded with the value $\mathrm{y}_{0}$. If the $\mathrm{RoCoF}$ is not changing apparently, the same amount of load will be taken away in the following step, which is $15 \%$. If the RoCoF is reduced to $\mathrm{x} \%$ of the previous RoCoF, the next step shedding amount is set to $\mathrm{x} \%$ of the last step value, that is $15 \%$ in this case.

\section{TEST MODEL}

The IEEE 33-bus distribution test system which is shown in Figure 3 above, is applied to implement and test the proposed methodology. The system consists of 32 loads with active power varying from $45 \mathrm{~kW}$ to $420 \mathrm{~kW}$. The system data of IEEE test system can be found in [18]. 4 groups of generators (1 CHP, 2 Diesel generators, 1 Wind turbine and 1 Solar panel) are located in Bus 18, 15, 14 and 33 respectively. The generators models are all refer to the template models in DIgSILENT. The capacity and governor parameters of each generator are shown in Tables II, III, and IV. The dynamic loads model is shown in Figure 4. For simplicity of the load model, the load voltage and frequency dependence parameters $k_{p v}, k_{q v}, k_{p f}$, and $k_{q f}$ are all set to 0.5 .

A sample of light and heavy loads classification with WTP ranking is given in Table $\mathrm{V}$. The loads are classified according to active power of each load in the network. The heavy loads category contains the loads with active power which is equal to or bigger than $90 \mathrm{~kW}$, while in the light loads category, the loads are smaller than $90 \mathrm{~kW}$. The load shedding sequence for the case in Table $\mathrm{V}$ is presented in Case 3 in following Section.

\section{CASE STUDY}

The test model was established by DIgSILENT PowerFactory. The configuration of the IEEE $12.66 \mathrm{kV}$ 33-Bus distribution system model is shown in Figure 3. The external grid is supporting the network with 2.2 MW real power and 2.3 MVAr

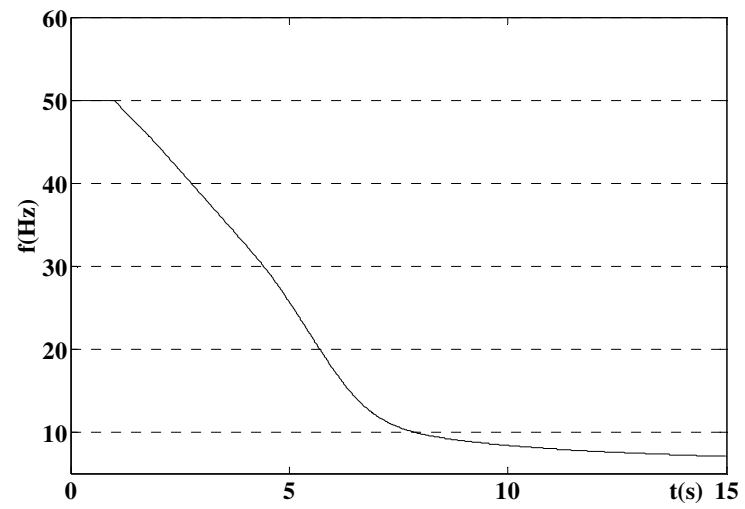

Fig. 5. Frequency response without load shedding

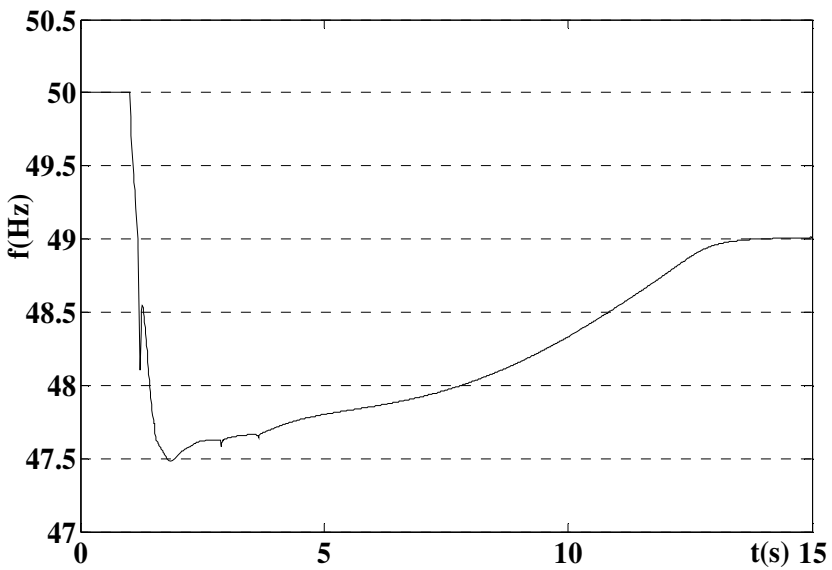

Fig. 6. Frequency response during load shedding 
reactive power. The simulation shows the impact of the load shedding schemes on the loss-of-main event.

The external grid was disconnected from the 33-bus system at 1s. Figure 5 gives the frequency response at CHP terminal without any load shedding. It can be seen in Figure 5 that the frequency decays from $50 \mathrm{~Hz}$ to $10 \mathrm{~Hz}$ within $7 \mathrm{~s}$ after islanding operation.

In this case, assuming that the larger loads which are ranked first by WTP and taken away first. After external grid disconnection, the first step of load shedding is activated at 1.07 $\mathrm{s}$ when the frequency drops to $49.5 \mathrm{~Hz}$. The recorded RoCoF value is -0.1044 p.u./s. Because of the time delay, the circuit breaker is in action at $1.17 \mathrm{~s}$, two heaviest loads at Bus 24 , and 25 are removed at the same time. When the frequency reaches to another threshold at $48 \mathrm{~Hz}$, the recorded RoCoF value is -0.0804 p.u./s, and the determined load shedding amount is around $670 \mathrm{~kW}$. After $0.1 \mathrm{~s}$ delay, the circuit breakers of loads at Bus 7, 30, and 32 are open at $1.5 \mathrm{~s}$. the frequency reaches to $47.5 \mathrm{~Hz}$ at $1.73 \mathrm{~s}$ with RoCoF at -0.0113 p.u./s, and the loads at Bus 11 and 15 are removed after 0.1s. After the third load shedding step, the frequency starts recovering, the second stage load shedding is activated. The RoCoF value drops below 0 at $2.8 \mathrm{~s}$ and load at Bus 6 is taken away. After 0.7s load at Bus 9 is taken away too as the RoCoF value turns to negative again. Figures 6 and 7 illustrate the Frequency and RoCoF deviation.

\section{DISCUSSIONS AND CONCLUSIONS}

A novel load shedding strategy for distribution network was proposed in this paper. The proposed strategy is based on classifying load into heavy and light groups which are ranked according to willingness to pay, frequency threshold and RoCoF. The method was applied to a low voltage distribution network 33-bus system and the investigation was conducted with DIgSILENT. Distribution network operators have obligations to satisfy the consumers' reliability requirement which can be reflected in consumers' willingness to pay for connection.

It can be concluded that the proposed scheme is an effective automatic load shedding strategy to reduce the total load shedding amount. A much better result can be achieved by reducing time delay and rising frequency threshold with RoCoF measurement.

\section{ACKNOWLEDGEMENTS}

Research in this paper is supported by the project, 'Novel Techniques and Their Applications for Development and Decision Support of Smart Distribution System', in State Grid Corporation of China. This support is very much appreciated.

The constructive comments from the reviewers are the most helpful.

\section{REFERENCES}

[1] Sevov, L, Zhao, T.W., Voloh, I. "The Power of IEC 61850: Bus-transfer and load-shedding applications", IEEE Industry Applications Magazine, No. 19 , No. 1, Jan.-Feb. 2013, pp. 60-67.

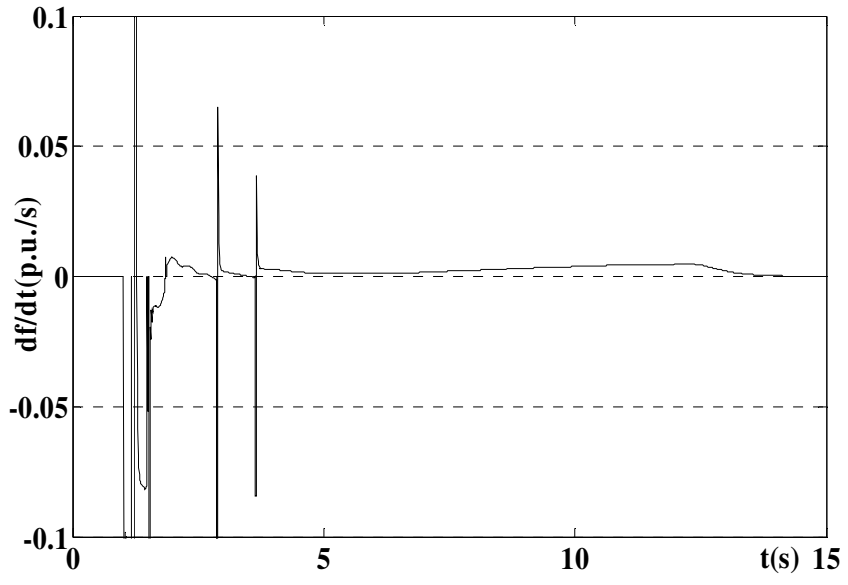

Fig. 7. RoCoF deviation during load shedding

[2] Jethwa, U.K.; Bansal, R.K.; Date, N.; Vaishnav,R. "Comprehensive load-shedding system", IEEE Transactions on Industry Applications, Vol. 46, No. 2, pp. 740-749.

[3] FarrokHShokooh, et al., "Intelligent load shedding-case study of the application in a large industrial facility", IEEE INDUSTRY APPLICATIONS MAGAZINE, Mar-Apr, 2011, pp. 44-53.

[4] Ying-Yi Hong, Po-Hsuang Chen, "Genetic-based underfrequency load shedding in a stand-alone power system considering fuzzy loads", IEEE Transactions on Power Delivery, Vol. 27, No. 1, Jan. 2012, pp. 87-95.

[5] Ceja-Gomez,F, Qadri, S.S.; Galiana, F.D. "Under-frequency load shedding via integer programming", IEEE Transactions on Power Systems, Vol.27, Issue: 3, Aug. 2012, pp1387-1394.

[6] Purnomo, M.H. ; Patria, C.A. ; Purwanto, E."Adaptive load shedding of the power system based on neural network", TENCON '02. Proceedings. 2002 IEEE Region 10 Conference on Computers, Communications, Control and Power Engineering, vol.3, pp.1778-1781

[7] V. V. Terzija, "Adaptive under-frequency load shedding based on the magnitude of the disturbance estimation," IEEE Trans. Power Systems, vol. 21, no. 3, pp. 1260-1266, Aug. 2006.

[8] Li Zhang; Jin Zhong, "UFLS Design by Using f and Integrating df/dt", Power Systems Conference and Exposition, pp1840-1844, 2006.

[9] V. Terzija, M. Djuric, and B. Kovacevic, "Voltage phasor and local system frequency estimation using newton type algorithm," IEEE Trans. Power Del., vol. 9, no. 3, pp. 1368-1374, Jul. 1994

[10] W. Li-yong, et al., "Study on load-shedding based on economic equivalent in power market," in Transmission and Distribution Conference and Exhibition: Asia and Pacific, 2005 IEEE/PES, 2005, pp. $1-5$.

[11] Deepak Kumar Singh, et al., "Optimal Load Shedding: An Economic Approach", TENCON 2010 - 2010 IEEE Region 10 Conference, pp.636 639, Nov. 2010.

[12] P. Mahat, Z. Chen, and B. Bak-Jensen, "Under frequency load shedding for an islanded distribution system with distribution generators," IEEE Trans. Power Del., vol. 25, no. 2, pp. 911-917, Apr. 2010.

[13] U.S. Department of Energy, National Energy Technology Laboratory "Understanding the Smart Grid: Features, Benefits and Costs", 2008.

[14] P. Wang, Y. Ding, and L. Goel"Reliability assessment of restructured power systems using optimal load shedding technique" (incomplete)

[15] P. M. Anderson and M. Mirheydar, "An adaptive method for setting underfrequency load shedding relays," IEEE Trans. Power Syst., vol.7, no. 2, pp. 647-655, May 1992.

[16] Olle I. Elgerd, Electric Energy System Theory-An Introduction, Second Edition, Mcgraw-Hill Book Company, USA, 1982.

[17] F. Carlsson and P. Martinsson, "Willingness to pay among swedish households to avoid power outages-A random parameter tobit model approach," Working Papers in Economics 154 Göteborg Univ., Dept. Econom., Dec. 2004. [Online]. Available: http://hdl.handle.net/2077/19626

[18] M. E. Baran, F. F. WU, 1989a, "Network Reconfiguration in Distribution Systems for Loss Reduction and Load Balancing", IEEE Trans. Power Delivery, vol. 4, no. 2 (Apr), pp. 1401-1407.

[19] ALSTOM, "Network Protection \& Automation Guide", Chapter 8-Protection Signaling and Intertripping, First Edition, July 2002 